\title{
Usability of eLearning interventions for teachers and day care workers in Africa: a scoping review protocol
}

\author{
*Monique De Wit, BOT (US), MOT (US) http://orcid.org/0000-000 I-8299-5707 \\ Clinical Lecturer Division of Occupational Therapy, Faculty of Medicine and Health Sciences, Stellenbosch University.
}

\section{Nicola Ann Plastow, BSc OT (UCT), MSc (Professional Health Studies) University of York St John, PGCert (TLHE) Brunel University London, PhD (Clinical Sciences) Brunel University London http://orcid.org/0000- 0002-3536-9I29}

Associate Professor and Head of Division of Occupational Therapy, Faculty of Medicine and Health Sciences, Stellenbosch University.

Introduction: Poor quality teacher training is one reason why children do not achieve school readiness. The Occupational Therapy Practice Framework (OTPF) includes teacher and day care provider training in teaching basic concepts to pre-schoolers, as an essential occupational therapy role. eLearning and mLearning are affordable, accessible, and usable formats for this training. This scoping review will provide a framework for improving the usability of eLearning and mLearning for teachers and day care providers of pre-schoolers. Methods and Analysis:This scoping review follows Arksey and O'Malley's (2005) framework and the PRISMA-ScR reporting guidelines using ERIC, CIHNAL, Africa Wide Information and Academic Search Premier databases, and a blind review process by two researchers. COVIDENCE software will be used to manage the review. Framework analysis using the nine usability criteria and WeftQDA will identify recommendations for eLearning and mLearning design.

Ethics and dissemination: This protocol is published to improve transparency and avoid duplication of work, as recommended in the PRISMA-SCR guidelines. The findings of this scoping review will be published in a peer-reviewed journal in 2020 and presented at conferences. The results will also inform the design of an mLearning application for teachers and day care providers within the African context.

Key words: early childhood development, pre-school, school readiness, teacher training, eLearning, mLearning, LMICs

\section{INTRODUCTION}

\section{Background to the problem}

In South Africa only $34 \%$ of children who enrolled in Grade I in $2007^{\prime}$ successfully completed high school in $2018^{2}$. One contributing factor to school failure and dropout is that children do not learn the necessary basic concepts needed for transitioning to Grade I. These basic concepts include numbers, colours, shapes, and body awareness. Recent research shows that as many as $50 \%$ of children entering Grade I in South Africa do not test ready for school ${ }^{3}$. There are various contributing factors to children not achieving general and academic developmental goals by age 6 . Studies point to lack of preschool teacher training as the number one reason why children do not achieve these milestones, even though they attend some form of pre-school or day care. Teacher training in necessary basic concepts at pre-school level would begin to address this problem ${ }^{4-6}$.

As occupational therapists, we address school readiness through individual therapy, teacher training and community programmes. The Occupational Therapy Practice Framework: Domain and Process (OTPF) ${ }^{7}$ guides the scope of occupational therapy services within early childhood settings, especially as it pertains to school readiness ${ }^{8}$. When school readiness is the outcome, occupational therapy services can focus on the cognitive and communication developmental areas. The role of the occupational therapist will then include promotion of basic concepts, such as attending to objects, sorting and classifying objects, and sequencing tasks to complete learning activities. When focusing on performance areas, fostering the development of pre-academic skills will be included for school readiness. Intervention can be directed at either the learners themselves, or the training of teachers and caregivers to reach these outcomes ${ }^{7,8}$. The accessibility and affordability of teacher training is increasingly addressed through online programmes and distance learning?.

eLearning, which includes online learning and mobile learning (mLearning), has become more prevalent in recent years. According to the GMSA Mobile Economy report of $2019^{10}$, cell phone penetration rates are at $44 \%$ for Sub-Saharan Africa, which means almost half of the population owns or has access to mobile devices. mLearning could be an affordable, accessible, and usable format of training for early childhood education teacher training which has the potential to improve the quality of teaching for all pre-school children. This is especially important for those teachers/day care providers who live and work in resource constrained communities, or who teach children who are growing up in poverty. Six out of every 10 children in South Africa live in poverty, which puts them at increased risk of not reaching developmental goals, such as school readiness ${ }^{4,9,10}$.

Usability testing is one step in the cycle of developing eLearning or mobile curriculum. The cycle includes designing, testing and implementing results until design and usability goals are met ${ }^{\prime \prime}$. Us- 
ability studies include various features that measure the quality of an online product or application. Usability has nine generic attributes, namely learnability, effectiveness, efficiency, comprehensibility, learning performance, satisfaction, simplicity, memorability and errors $^{12}$. Davids et al ${ }^{13-15}$ emphasise the need for proper evaluation of online training programs, which includes heuristic evaluation of the design and process of development, to ensure that the intended learning outcomes are reached. The intended learning outcome of mLearning for day care providers, is an increase in knowledge of teaching the basic concepts necessary for school readiness. Therefore, proper evaluation of mLearning programs are essential ${ }^{1-14}$.

In 2017, Ackerman ${ }^{16}$ published the results of data analysis from a US-based, online day care teacher training provider to investigate who participates in online training for day care providers, what the focus is of the training being offered and which topics show higher participation rates. It was determined that in the USA, online training meets the needs specifically of day care providers who lack in-person training options due to high cost of programmes, geographical accessibility constraints, work obligations, or who prefer the convenience of learning at their own pace in their own homes. Of the courses offered in 2016 , roughly $75 \%$ were at a beginner level and one hour in duration. The current online training format and level of training aims at increasing knowledge, whereas intermediate and advanced level training is needed to improve teaching practices as well as improve the learning outcomes of the children ${ }^{16}$.

In preparation for developing a mobile application to teach basic concepts, we want to understand the key factors that influence design and usability of eLearning and mLearning programmes for day care providers in low- and middle-income countries (LMICs) such as South Africa. The results of a scoping review will help us understand who participates in online training for day care providers, how they access the information and what their needs are for the format and design of online training.

\section{Aim and objectives}

The objectives of this scoping review are three-fold:

- To summarize and map the available peer reviewed literature on eLearning and mLearning for day care providers in LMICs in the last 10 years

- To identify research gaps within usability studies for eLearning and mLearning of day care providers in LMICs

- To make recommendations for future usability studies for eLearning and mLearning of day care providers in LMICs

\section{METHODS AND ANALYSIS}

Arksey and O'Malley ${ }^{17}$ developed a methodological framework for scoping reviews, with additional recommendations for each stage suggested by Levac, Colquhoun and O'Brien ${ }^{18}$. We will follow the Arksey and O'Malley ${ }^{17}$ framework to complete the scoping review and the PRISMA extension for scoping reviews (PRISMA ScR): Checklist and explanation ${ }^{19}$, will be used to complete the write-up of this scoping review.

\section{Stage I: Identifying the research question}

The research question was developed with our target population and context in mind, but also stated as broadly as possible, as to not exclude any relevant studies.

The question is: What is known about the usability of mobile or eLearning interventions, that improve the knowledge, skills and attitudes among day care providers in $L M I C$, to promote early childhood development of 3-6-year olds?
Table I: Inclusion and Exclusion Criteria

\section{Inclusion criteria}

- Training of day care providers (pre-school teachers for 3-6year olds, including grade $\mathrm{R}$ and foundation phase)

- eLearning or mLearning element, thus online training

\section{Exclusion criteria:}

- Training of other than ECD or foundation phase teachers (3-6-year olds)

- No eLearning element

- Study not in Africa or LMIC

- Study not published in English

- Training of teachers for skills other than attitude, knowledge and skill of early childhood curriculum

- Using technology to teach children

- Children using the technology

\section{Stage 2: Identifying relevant studies}

The search will include three phases, namely: a database search, hand-searching of relevant journals and screening of reference lists of already included articles in previous phases. We chose ERIC, CIHNAL, Africa-Wide Information and Academic Search Premier as relevant databases for the search as these include research in the field of education, allied healthcare professions, and research conducted in Africa.

We selected the parameters to limit our search to studies published in peer-reviewed journals, in English, between January 2009 and January 2019. Peer-reviewed journals were selected to ensure the inclusion of high-quality primary sources. Development of hardware and software are a continuously changing landscape, therefore, only the last 10 years of published research will be considered for this scoping review. This timeframe also coincides with the emergence of smartphones within the African context ${ }^{10}$. We used the definition of Low- and Middle-Income Countries (LMICs) as suggested by the World Bank's list of $\mathrm{LMICs}^{20}$.

After considering our research question, we developed the following terms in consultation with a librarian in order of inclusion importance. These will be included in the systematic search: "Early childhood development" OR pre-school OR teacher OR day care I. Train* OR teach* OR learn*

2. e-Learning OR mlearning OR online OR mobile

3. Africa OR LMIC

When the initial search is done, duplicates of exact results will be automatically removed by the search engine.

Once the total unique studies are identified using our search string, results will be uploaded to COVIDENCE, a review management software. The first reviewer will consider all the titles against the inclusion and exclusion criteria as described in Table I, after which selected articles will be included for the abstract screen. Journals that publish research on technology will be hand-searched using the same parameters and key-word combination, and additional articles will be selected for abstract screening.

\section{Stage 3: Study selection}

Only the first reviewer will complete the next phase by reading the abstracts, considering the inclusion and exclusion criteria, and selecting articles for full text screening. It is important to note that this is part of an iterative process and as inclusion and exclusion criteria develop, studies will be added or eliminated.

Both reviewers will complete the next phase of full text reading. Studies that meet all the inclusion criteria according to both reviewers, will then be added to the final list of articles for this scoping 
Table II: Data extraction sample worksheet

\begin{tabular}{|c|c|c|c|c|}
\hline \multirow{4}{*}{ 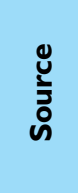 } & \multicolumn{4}{|c|}{ Name of article } \\
\hline & \multicolumn{4}{|l|}{ Author } \\
\hline & \multicolumn{4}{|c|}{ Date published } \\
\hline & \multicolumn{4}{|l|}{ Journal } \\
\hline \multirow{8}{*}{ 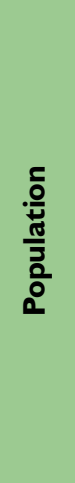 } & \multicolumn{2}{|c|}{ Geographical area } & \multirow{8}{*}{ 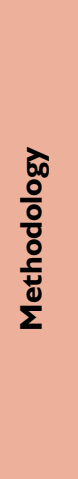 } & Method \\
\hline & Teaching & text & & Methodology \\
\hline & Number & articipants & & Level of evidence ${ }^{21}$ \\
\hline & \multicolumn{2}{|c|}{ Age of participants } & & Outcome measures used \\
\hline & \multicolumn{2}{|c|}{ Training program } & & $\begin{array}{l}\text { Design model or frame- } \\
\text { work used }\end{array}$ \\
\hline & \multicolumn{2}{|c|}{ Age of children being taught } & & Topics taught within ECD \\
\hline & \multicolumn{2}{|c|}{ Level of teacher training } & & mLearning/eLearning/Video \\
\hline & \multicolumn{2}{|c|}{ Type of program } & & Language used \\
\hline \multirow{5}{*}{ 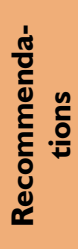 } & \multirow{5}{*}{ 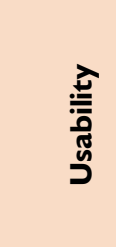 } & \multicolumn{2}{|l|}{ Learnability } & Satisfaction \\
\hline & & \multicolumn{2}{|l|}{ Effectiveness } & Memorability \\
\hline & & \multicolumn{2}{|l|}{ Efficiency } & Simplicity \\
\hline & & \multicolumn{2}{|c|}{ Comprehensibility } & Errors \\
\hline & & \multicolumn{2}{|c|}{ Learning performance } & \\
\hline
\end{tabular}

Table III: Study timeline

\begin{tabular}{|c|c|}
\hline $\begin{array}{l}\text { Stage I: } \\
\text { Identifying } \\
\text { the research } \\
\text { question }\end{array}$ & $\begin{array}{l}\text { We have already developed and identified the research } \\
\text { question, in order to reach an objective of identifying } \\
\text { relevant research to support and inform the develop- } \\
\text { ment of an mLearning product for training day care } \\
\text { providers. }\end{array}$ \\
\hline $\begin{array}{l}\text { Stage 2: } \\
\text { Identifying } \\
\text { relevant } \\
\text { studies }\end{array}$ & $\begin{array}{l}\text { A systematic process will be followed, as described } \\
\text { by Bartels }{ }^{22} \text {, to complete a systematic search of the } \\
\text { literature. This includes deciding on the databases to } \\
\text { include, the search parameters, and the keywords. }\end{array}$ \\
\hline $\begin{array}{l}\text { Stage 3: } \\
\text { Study selec- } \\
\text { tion }\end{array}$ & $\begin{array}{l}\text { We will use COVIDENCE to assist us in the system- } \\
\text { atic process of study selection. This allows for both } \\
\text { researchers to be included and given access to the } \\
\text { relevant studies at the relevant stages as decided } \\
\text { beforehand. The title screen and abstract screen } \\
\text { will be completed by the first reviewer only. The } \\
\text { full-text screen will be completed by both reviewers. } \\
\text { Title screen and abstract screen will be completed in } \\
\text { Months I and } 2 \text {. The full-text screen will be com- } \\
\text { pleted in Month } 3 \text {. }\end{array}$ \\
\hline $\begin{array}{l}\text { Stage 4: } \\
\text { Charting the } \\
\text { data }\end{array}$ & $\begin{array}{l}\text { As studies are identified to be included, the data ex- } \\
\text { traction process will commence. The data extraction } \\
\text { worksheet (Table II) will be used and will also expand } \\
\text { during this iterative process from Month } 4 \text { to } 6 \text {. } \\
\text { Framework analysis will be used to extract and chart } \\
\text { the recommendations. The usability framework con- } \\
\text { sists of various attributes, according to the international } \\
\text { standards for systems and software engineering }{ }^{23} \text {. }\end{array}$ \\
\hline $\begin{array}{l}\text { Stage 5: } \\
\text { Collating, } \\
\text { summarising } \\
\text { and reporting } \\
\text { the results }\end{array}$ & $\begin{array}{l}\text { The descriptive and narrative summary of the data will be } \\
\text { presented in a second article and submitted for publica- } \\
\text { tion in Month 9. Framework synthesis will be utilized as } \\
\text { a structured approach to organize and analyse our data }{ }^{24} \text {. } \\
\text { Once the relevant information is used to answer the } \\
\text { research question, the information will be used to form } \\
\text { the basis to inform the design and usability aspects of a } \\
\text { mobile training application to train day care providers. }\end{array}$ \\
\hline
\end{tabular}

review. All reference lists of studies selected for final inclusion will be scanned for additional articles that may meet the inclusion criteria. These articles will be reviewed and included if appropriate. The COVIDENCE software will be used to maintain an audit trail of all decisions made for inclusion and exclusion by each of the reviewers. The software will also generate the final PRISMA flow diagram indicating the various stages of article review.

\section{Stage 4: Charting the data}

The reviewers developed a data-charting form, using Excel. Data will be extracted on characteristics of the population, the methodology and the results and recommendations. Table II presents a preliminary set of information that we will extract from each study. As we are using an iterative process, the data-charting form may be modified as we proceed through the data extraction process and more information is available from each study. Anticipated changes may be within the aspects of usability, as we will be looking at these recommendations from each included study. During the data extraction and charting process, it is once again very important to reflect on the research question and focus on data from each study that will shed light on the design and usability of the elearning programs used by the intended population. The changes in this worksheet will be tracked and described during the reporting of the scoping review results.

\section{Stage 5: Collating, summarising, and reporting the results}

Results will be reported in a descriptive and narrative summary. We will report on the demographic description of the population, as well as which geographical areas within Africa in which research has been conducted. Other areas of focus for reporting the results will be on the quality of the research included ${ }^{21}$, as well as trends in how studies on mLearning and eLearning are executed and reported. To answer the research question, the analysis will mainly focus on the usability aspects of training programs for day care providers in LMICs. Where possible, the recommendations for good design evident in each article will be clustered into the 9 attributes of usability. These aspects of usability will be used as a priori framework to analyse and organize the data. The findings of the scoping review will be published in an article, as well as inform the design and usability considerations for further research on development of a mobile training programme for day care providers in a LMIC.

\section{Patient and public involvement}

Although Arksey and O'Malley ${ }^{17}$ as well as Levac et al ${ }^{18}$ suggest the optional step to involve consumers and stake holders in the scoping review, we have not included them. End users and stake holders will be included in the development of a product based on the results of this scoping review.

\section{Ethics and Dissemination}

This review does not involve primary data collection, additional institutional ethics review, or informed consent procedures.

\section{CONCLUSION}

According to the OTPF 7 , the teaching of basic concepts and working towards school readiness for pre-schoolers, are fundamental to occupational therapy services in schools and in private practice. This service can be delivered on an individual basis or be directed at the training of day care providers and caregivers. To make this training accessible and affordable to day care providers and caregiv- 
ers, especially in resource constrained areas, eLearning and mLearning products must be considered and evaluated for effectiveness.

Authors like Davids et $\mathrm{al}^{13-15}$, emphasised the need for proper usability studies and heuristic evaluation of eLearning and mLearning products, to ensure that the learning outcomes can be achieved by the intended population. This scoping review is necessary to assess what is known about the usability aspects for eLearning and $\mathrm{mLearning}$ products used by day care providers for their own formal learning or professional development. This scoping review will help summarize the current peer reviewed literature, identify the research gaps within usability studies and inform future design and usability, as applicable to mLearning products for day care providers in LMICs. The results of this scoping review will also form part of the literature review for the development and testing of a mobile application to train day care providers to teach basic concepts, all within a LMIC context $\mathrm{t}^{11-13}$.

Existing literature published in the last 10 years will be analysed and therefore, ethics approval was not required. The scoping review protocol and publication of the protocol is an important step in this scoping review, to ensure transparency and reduce duplication of work. It will be useful to determine what is known about the design and usability of eLearning and mLearning product used by teachers and day care providers in LMICs. mLearning in general is an affordable, accessible, and convenient method for formal training and professional development and should be informed by research to move forward with successful outcomes.

\section{REFERENCES}

I. Department of Education. Education Statistics in South Africa. Pretoria, http://www.dhet.gov.za/DHET Statistics Publication/DoE Stats at a Glance 2007.pdf (2009).

2. Department of Basic Education. National Senior Certificate 2018 Highlights Report. Pretoria, https:/www.gov.za/sites/default/files/ gcis_document/201810/dbe-2017/8-annual-report.pdf (2019).

3. Janse van Rensburg $O$. The school readiness performance of a group of Grade R learners in primary schools in the Gauteng Province of South Africa. South African J Child Educ. 20I5; 5: 106-124. http://doi.org/10.4102/sajce.v5il.352

4. Ramey CT, Ramey SL. Early Learning and School Readiness: Can Early Intervention Make a Difference? Merrill Palmer Q. 2004; 50: 47I-49I. http://doi.org/I0.1353/mpq.2004.0034

5. Mashburn AJ, Pianta RC, Hamre BK, et al. Measures of Classroom Quality in Prekindergarten and Children's Development of Academic, Language, and Social Skills. Child Dev. 2008; 79: 732-749. http://doi.org/I0.1 I I I/j.1467-8624.2008.01 I54.x

6. Atmore E, van Niekerk L, Ashley-Cooper M. Challenges Facing the Early Childhood Development Sector in South Africa.

http://www.nda.org.za/docs/Challenges-facing-ECD-Sector-in-SAProf-Atmore.pdf (2012).

7. American Occupational Therapy Association. Occupational therapy practice Framework: Domain and process 3rd Edition. Am J Occup Ther. 2014; 68: 48. http://doi.org//0.50I4/ajot.2014.682006

8. American Occupational Therapy Association. Occupational Therapy Services in Early Childhood and School-Based Settings. Am J Occup Ther. 20I I; 65: S46-S54. http://doi.org/10.5014/ajot.201 I.65s46

9. Delany A, Jehoma S, Lake L. South Afican Child Gauge 2016. Cape Town: Department of Planning, Monitoring and Evaluation, http:// www.ci.uct.ac.za/sites/default/files/image_tool/images/367/Child_ Gauge/2006/Book_Child_Gauge_2016_lowres.pdf (2016).

10. GSMA. The Mobile Economy. Sub-Saharan Africa. 2019; I-35. https://www.gsma.com/betterfuture/wp-content/uploads/2019/10/201909-24-a60d654|465e8656 If37f0f77ebee0f7-I.pdf

II. Davids M. Development and evaluation of a multimedia e-learning resource for electrolyte and acid-base disorders. Adv Physiol Educ. 201 I; 295-306. http://doi.org/10.1 I52/advan.00127.2010.

12. Zhang D, Adipat B. Challenges, Methodologies, and Issues in the Usability Testing of Mobile Applications. Int J Hum Comput Interact. 2005; 18: 293-308. http://doi.org//0.1207/s 15327590ijhcl803_3

13. Davids MR, Chikte UME, Halperin ML. Effect of improving the usability of an e-learning resource: a randomized trial. AJP Adv Physiol Educ. 2014; 38: 155-160. http://doi.org/10.1 I52/advan.00119.2013

14. Davids MR, Chikte UME, Halperin ML. An efficient approach to improve the usability of e-learning resources: the role of heuristic evaluation. AJP Adv Physiol Educ .2013; 37: 242-248. http://doi.org/I0.1 I52/advan.00043.2013

15. Davids MR, Chikte U, Grimmer-Somers K, et al. Usability testing of a multimedia e-learning resource for electrolyte and acid-base disorders. Br J Educ Techno.I 20 I4; 45: 367-38I. http://doi.org/10.1 I I l/bjet. 12042

16. Ackerman DJ. Online child care training in the United States: a preliminary investigation of who participates, what is offered, and on which topics the workforce is focusing. Int J Child Care Educ Policy. 2017; II: 12. http://doi.org//0.1 186/s40723-017-0037-7

17. Arksey H, O'Malley L. Scoping Studies: Towards a Methodological Framework. Int J Soc Res Methodol. 2005; 8: 19-32. http://doi.org/10.1017/S0922156508005621

18. Levac D, Colquhoun H, O'Brien K. Scoping Studies: advancing the methodology. Syst Rev J. 2015; 4: I-9. http://doi.org/I0.1029/2003JD004 I73.Aires

19. Garritty C, Moher D, Aldcroft A, et al. PRISMA Extension for Scoping Reviews (PRISMA-ScR): Checklist and Explanation. Ann Intern Med. 2018; 169: 467. http://doi.org/10.7326/m/8-0850

20. https://datahelpdesk.worldbank.org/knowledgebase/articles/9065।9world-bank-country-and-lending-groups.

21. Merlin T, Weston A, Tooher R. Extending an evidence hierarchy to include topics other than treatment : revising the Australian ' levels of evidence'. 2009; 8: I-8. http://doi.org/10.1 I86/I47/-2288-9-34

22. Bartels EM. How to perform a systematic search. Best Pract Res Clin Rheumatol. 2013; 27: 295-306.

http://doi.org/10.1016/j.berh.2013.02.00।

23. International Standards Organization/International Electrotechnical Commission. System and software quality models. https://pdfs.semanticscholar.org/57a5/b99eceff9da205e244337c9f4678b5b23d25.pdf (20II).

24. Barnett-Page $E$, Thomas J. Methods for the synthesis of qualitative research: A critical review. BMC Med Res Methodol; 9. Epub ahead of print 2009. http://doi.org/10.1 I86/I47/-2288-9-59

\section{ROLES OF AUTHORS:}

Monique De Wit is the first author and this article is the first of two as part of her Master's Degree at the Stellenbosch University.

Nicola Ann Plastow is the second author and acted as supervisor for the thesis, and contributed to the study as the second reviewer where indicated.

Corresponding Author

*M. de Wit

Email: modewit@gmail.com 